\title{
Side-by-side versus stent-in-stent bilateral stenting for malignant hilar biliary obstruction: a meta-analysis
}

\author{
Liang Chen ${ }^{1}$, Guo-Ming Gao', Dong-Lu Li ${ }^{2}$, Zhong-Ke Chen ${ }^{3}$ \\ ${ }^{1}$ Department of Interventional Therapy, Tianshui Second People's Hospital, Tianshui, China \\ ${ }^{2}$ Department of Anatomy, Gansu Medical College, Pingliang, China \\ ${ }^{3}$ Department of Interventional Therapy, Affiliated Hospital of Gansu Medical College, Pingliang, China
}

Videosurgery Miniinv 2022; 17 (2): 279-288

DOI: https://doi.org/10.5114/wiitm.2021.112477

\begin{abstract}
Introduction: Both side-by-side (SBS) and stent-in-stent (SIS) bilateral stenting have been used for patients with malignant hilar biliary obstruction (MHBO). However, it is unclear which technique is better.

Aim: This meta-analysis is conducted to investigate the clinical efficacy and safety of SBS and SIS bilateral stenting for patients with $M H B O$.

Material and methods: Relevant studies were searched in PubMed, Embase, Cochrane Library, Wanfang, VIP, and CINK databases. The timeline for the searches was from the establishment of the database to September 2021. The relative outcomes are pooled.

Results: A total of 7 studies fulfilled the inclusion criteria and entered into this meta-analysis. The pooled technical success rate was significant higher in the SIS group than that in the SBS group $(p=0.04)$. The pooled early complication rate was significantly lower in the SIS group than in the SBS group $(p=0.04)$. The pooled stent re-obstruction rate was significantly lower in the SBS group than in the SIS group $(p=0.04)$. The pooled stent patency duration was significantly longer in the SBS group than in the SIS group $(p=0.01)$. The pooled functional success rates $(p=0.79)$, total complication rates $(p=0.34)$, and overall survival duration $(p=0.27)$ were comparable between 2 groups. Egger test did not show any publication bias.

Conclusions: When comparing the SBS and SIS bilateral stenting for patients with MHBO, although SIS technique may have the superiorities of technical success and early complication rates, the longer stent patency was achieved by the SBS technique.
\end{abstract}

Key words: side-by-side, stent-in-stent, bilateral.

\section{Introduction}

Malignant hilar biliary obstruction (MHBO) is a disorder caused by primary or metastatic hepato-biliary tumours [1-5]. Approximately $70 \%$ of patients with $\mathrm{MHBO}$ are inoperable due to the advanced tumour stage [6]. Endoscopic or percutaneous biliary stenting has been widely used for patients with inoperable MHBO in order to relieve the symptoms of jaundice [7-10].
Asia-Pacific Working Group recommended that biliary stent should drain more than $50 \%$ of the entire liver [7]. Therefore, bilateral stenting is preferred among a majority of researchers [11-17]. There are two commonly used bilateral stenting techniques, which include side-by-side (SBS) and stent-in-stent (SIS) strategies. However, few comparative studies of the two techniques have been performed and they have yielded inconsistent findings [11-17],

\section{Address for correspondence}

Zhong-Ke Chen MD, Department of Interventional Therapy, Affiliated Hospital of Gansu Medical College, Pingliang, China,

e-mail: chenzhongke1975@163.com 
making the relative superiority of these techniques uncertain [10]. Therefore, a meta-analysis should be performed to detect the comparative results between SBS and SIS techniques.

\section{Aim}

This meta-analysis is conducted to investigate the efficacy and safety of SBS and SIS bilateral stenting for MHBO patients.

\section{Material and methods}

\section{Study selection}

This meta-analysis was performed as per the Preferred Reporting Items for Systematic Reviews and Meta-Analyses statement [18]. This meta-analysis was registered at INPLASY.COM (No. INPLASY2021100031).

Relevant articles were searched in PubMed, Embase, Cochrane Library, Wanfang, VIP, and CINK using the following strategy: (((side-by-side OR (SBS)) AND ((stent-in-stent) OR (SIS))) AND (((hilar OR (biliary)) OR (Cholangiocarcinoma)). The timeline for the searches was from the establishment of the database to September 2021.

Inclusion criteria included:

a) type of study: comparative studies,

b) disease: $\mathrm{MHBO}$,

c) types of interventions: SBS versus SIS bilateral metal stenting,

d) languages: all.

Exclusion criteria included:

a) single-arm studies,

b) patients who underwent plastic stenting,

c) case reports, letters, and reviews.

\section{Data extraction}

Two researchers independently extracted the relative data from the included studies, and the bifurcation was solved by a third researcher. The baseline data of each study included first author's name, publication year, country, types of design, cancer types, stenting approaches, Bismuth types, sample size, age, and gender. The outcomes of each study included technical success, functional success, complication rates, re-obstruction rates, stent patency, and overall survival (OS).

\section{Quality assessment}

Potential bias was examined with the Cochrane risk of bias tool for randomized controlled trials
(RCTs). The items of Cochrane risk of bias tool include performance, attrition, detection, selection, reporting, and other sources of bias.

Non-RCTs were assessed by the 9-point Newcastle-Ottawa scale (NOS) [19], with studies exhibiting low, intermediate, or high levels of risk receiving scores of $\geq 7,4-6$, and $<4$, respectively. The items of NOS include selection (4 points), comparability (2 points), and exposure (3 points).

\section{Endpoints and definitions}

Meta-analysis primary endpoints include stent re-obstruction rate and stent patency duration. The secondary endpoints include technical success rates, functional success rates, complication rates, and OS. SBS technique involves parallel stenting using two stents [10], and SIS technique involves placing a second SEMS contralaterally through the first stent mesh [10]. Successful bilateral stent deployment in an appropriate position with the ability of contrast to readily flow through the stent and into the duodenum was used to define technical success [17]. Functional success is defined as at least a $30 \%$ reduction in total bilirubin within 2 weeks postoperatively, or $50 \%$ within 4 weeks [20]. Stent patency duration is calculated from the stent insertion to stent re-obstruction or death. OS is calculated from the stent insertion to death.

\section{Statistical analysis}

RevMan v5.3 and Stata v12.0 were used for this meta-analysis. Pooled odds ratios (ORs) with 95\% confidence intervals (Cls) was calculated for dichotomous variables, and continuous variables were calculated by mean differences (MDs) with $95 \% \mathrm{Cls}$. Pooled stent patency duration and OS were calculated by hazard ratios (HRs) with $95 \% \mathrm{Cl}$. Heterogeneity was determined by the $I^{2}$ statistic and Q test. $I^{2}>50 \%$ was defined as high heterogeneity, and then the random effect model was used; otherwise, fixed effects models were used. Sources of heterogeneity were evaluated by sensitivity and subgroup analyses. Egger test was used to evaluate publication bias. $P<0.05$ was the threshold for publication bias significance.

\section{Results}

\section{Included studies}

A total of 235 studies were initially identified from the databases. Finally, 7 studies fulfilled the 


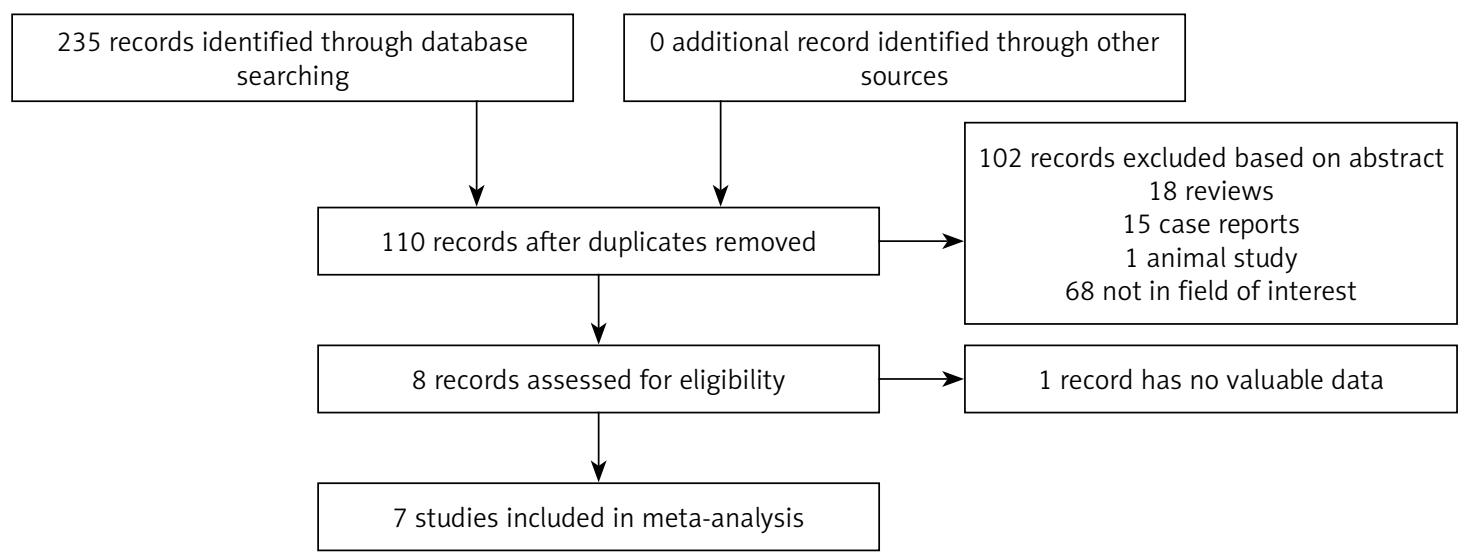

Figure 1. The flowchart of this study

inclusion criteria and entered into this meta-analysis (Figure 1). Among these 7 studies (Table I), 199 patients underwent SBS bilateral stenting and 180 patients underwent SIS bilateral stenting. Six studies were retrospective [11-13, 15-17] and one study was RCT [14]. Five studies used the endoscopic approach [11-15] and 2 studies used the percutaneous approach $[16,17]$. Two studies included Bismuth I-IV patients [12, 15], 4 studies included Bismuth II-IV patients [11, 13, 16, 17], and one study included Bismuth III-IV patients [14]. The raw data of the treatment outcomes are shown in Table II.
The included RCT has a high risk of performance bias and unclear risk of detection and other bias (Figure 2). The NOS for the retrospective NOS ranged from 7 to 8 (Table I).

\section{Technical success}

Six studies (SBS group: 180; SIS group: 158) reported the technical success rates [11, 13-17]. The pooled technical success rate was significantly higher in the SIS group than in the SBS group $(100 \%$ vs. $96.1 \%, p=0.04$, Figure $3 \mathrm{~A})$. The het-

Table I. Characteristics of the included studies

\begin{tabular}{|c|c|c|c|c|c|c|c|c|c|}
\hline $\begin{array}{l}\text { Study/year/ } \\
\text { country }\end{array}$ & Study design & $\begin{array}{l}\text { Cancer } \\
\text { types }\end{array}$ & $\begin{array}{c}\text { Stent } \\
\text { approach }\end{array}$ & $\begin{array}{l}\text { Bismuth } \\
\text { types }\end{array}$ & Groups & $\begin{array}{l}\text { Sample } \\
\text { size }\end{array}$ & $\begin{array}{c}\text { Age } \\
\text { [years] }\end{array}$ & $M / F$ & NOS \\
\hline \multirow{2}{*}{$\begin{array}{l}\text { Ishigaki/2020/ } \\
\text { Japan [11] }\end{array}$} & \multirow[t]{2}{*}{ Retrospective } & \multirow{2}{*}{$\begin{array}{l}\mathrm{C}, \mathrm{G}, \mathrm{P}, \\
\mathrm{MD}\end{array}$} & \multirow[t]{2}{*}{ Endoscopic } & \multirow[t]{2}{*}{ II-IV } & SBS & 24 & 74 & 13/11 & \multirow[t]{2}{*}{8} \\
\hline & & & & & SIS & 40 & 72 & $22 / 18$ & \\
\hline \multirow{2}{*}{$\begin{array}{l}\text { Kim/2012/ } \\
\text { Korea [12] }\end{array}$} & \multirow[t]{2}{*}{ Retrospective } & \multirow{2}{*}{$\begin{array}{c}C, G, H \\
M D\end{array}$} & \multirow[t]{2}{*}{ Endoscopic } & \multirow[t]{2}{*}{ I-IV } & SBS & 19 & 64.2 & $11 / 8$ & \multirow[t]{2}{*}{8} \\
\hline & & & & & SIS & 22 & 65 & $17 / 5$ & \\
\hline \multirow{2}{*}{$\begin{array}{l}\text { Law/2013/ } \\
\text { USA [13] }\end{array}$} & \multirow[t]{2}{*}{ Retrospective } & \multirow{2}{*}{$\begin{array}{l}\text { C, other, } \\
\text { MD }\end{array}$} & \multirow[t]{2}{*}{ Endoscopic } & \multirow[t]{2}{*}{ II-IV } & SBS & 17 & \multirow{2}{*}{$\begin{array}{l}68 \\
\text { for all }\end{array}$} & \multirow{2}{*}{$\begin{array}{l}19 / 5 \\
\text { for all }\end{array}$} & \multirow[t]{2}{*}{7} \\
\hline & & & & & SIS & 7 & & & \\
\hline \multirow{2}{*}{$\begin{array}{l}\text { Lee/2019/ } \\
\text { Korea [14] }\end{array}$} & \multirow[t]{2}{*}{ RCT } & \multirow[t]{2}{*}{ C, G } & \multirow[t]{2}{*}{ Endoscopic } & \multirow[t]{2}{*}{ III/IV } & SBS & 35 & 72.5 & 21/14 & \multirow[t]{2}{*}{-} \\
\hline & & & & & SIS & 34 & 74.5 & $15 / 19$ & \\
\hline \multirow{2}{*}{$\begin{array}{l}\text { Naitoh/2012/ } \\
\text { Japan [15] }\end{array}$} & \multirow[t]{2}{*}{ Retrospective } & \multirow{2}{*}{$\begin{array}{l}\text { C, G, } \\
\text { other }\end{array}$} & \multirow[t]{2}{*}{ Endoscopic } & \multirow[t]{2}{*}{ I-IV } & SBS & 28 & 72 & $11 / 17$ & \multirow[t]{2}{*}{8} \\
\hline & & & & & SIS & 24 & 75 & $14 / 10$ & \\
\hline \multirow{2}{*}{$\begin{array}{l}\text { Xu/2021/ } \\
\text { China [16] }\end{array}$} & \multirow[t]{2}{*}{ Retrospective } & \multirow{2}{*}{$\begin{array}{l}\mathrm{C}, \mathrm{G}, \mathrm{H} \text {, } \\
\text { other }\end{array}$} & \multirow[t]{2}{*}{ Percutaneous } & \multirow[t]{2}{*}{ II-IV } & SBS & 38 & 63 & 20/18 & 8 \\
\hline & & & & & SIS & 26 & 65 & $11 / 15$ & \\
\hline Zhou/2020/ & Retrospective & $\mathrm{C}, \mathrm{G}, \mathrm{H}$ & Percutaneous & II-IV & SBS & 38 & 63 & 19/19 & 8 \\
\hline China [17] & & other & & & SIS & 27 & 65.3 & $10 / 17$ & \\
\hline
\end{tabular}

NOS - Newcastle-Ottawa scale, RCT - randomized controlled trial, $C$ - cholangiocarcinoma, G-gallbladder cancer, $H$ - hepatocellular carcinoma, $P$ - pancreatic cancer, MD - metastatic diseases, SBS - side-by-side, SIS - stent-in-stent, $M$ - male, F-female. 
Table II. Characteristics of the treatment outcomes

\begin{tabular}{|c|c|c|c|c|c|c|c|c|c|}
\hline Study & Groups & TS (\%) & FS (\%) & TC (\%) & EC (\%) & RO (\%) & AT $(n)$ & Patency & OS \\
\hline \multirow[t]{2}{*}{ Ishigaki [11] } & SBS & 95.8 & 100 & 60.9 & 47.8 & 47.8 & 17 & $205 d$ & $381 \mathrm{~d}$ \\
\hline & SIS & 100 & 92.5 & 32.5 & 22.5 & 47.5 & 26 & $169 d$ & $238 d$ \\
\hline \multirow[t]{2}{*}{ Kim [12] } & SBS & NG & 78.9 & 21.1 & 15.8 & 21.1 & NG & $118 \mathrm{~d}$ & $146 d$ \\
\hline & SIS & NG & 94.1 & 13.6 & 9.1 & 18.2 & NG & $134 \mathrm{~d}$ & $225 d$ \\
\hline \multirow[t]{2}{*}{ Law [13] } & SBS & 100 & NG & $N G$ & $N G$ & 52.9 & $N G$ & $N G$ & NG \\
\hline & SIS & 100 & NG & NG & NG & 42.9 & NG & NG & NG \\
\hline \multirow[t]{2}{*}{ Lee [14] } & SBS & 91.4 & 90.6 & 31.3 & 12.5 & 37.5 & 9 & $262 d$ & $221 d$ \\
\hline & SIS & 100 & 94.1 & 23.5 & 11.8 & 44.1 & 9 & $253 d$ & $209 d$ \\
\hline \multirow[t]{2}{*}{ Naitoh [15] } & SBS & 89.3 & 96.0 & 39.3 & 12.0 & 20.0 & 16 & $155 d$ & $198 d$ \\
\hline & SIS & 100 & 100 & 8.3 & 4.2 & 41.7 & 15 & $104 d$ & $159 d$ \\
\hline \multirow[t]{2}{*}{$\mathrm{Xu}[16]$} & SBS & 100 & 92.1 & 21.1 & $N G$ & 18.4 & 20 & $149 d$ & $155 d$ \\
\hline & SIS & 100 & 88.5 & 34.6 & NG & 38.5 & 13 & $75 d$ & $143 d$ \\
\hline \multirow[t]{2}{*}{ Zhou [17] } & SBS & 100 & 92.1 & 21.1 & $N G$ & 18.4 & 6 & $149 d$ & $155 d$ \\
\hline & SIS & 100 & 88.9 & 33.3 & $N G$ & 37.0 & 4 & $75 d$ & $143 d$ \\
\hline
\end{tabular}

SBS - side-by-side, SIS - stent-in-stent, TS - technical success, FS - functional success, TC - total complication, EC - early complication, RO - re-obstruction, $A T$ - anticancer treatment, OS - overall survival, NG - not given.

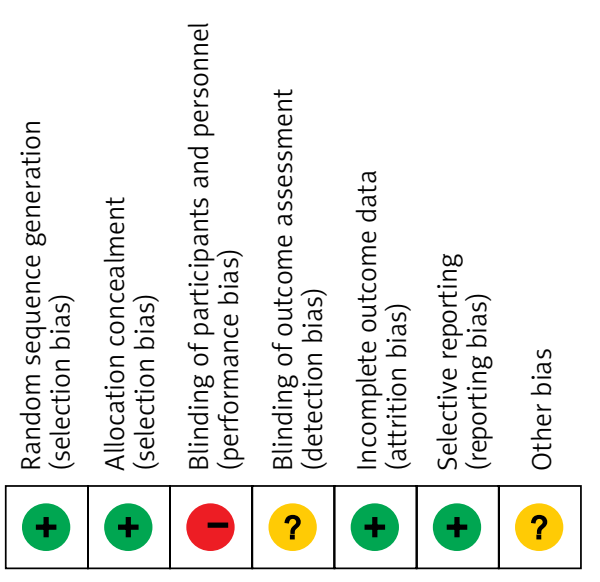

Figure 2. Cochrane's risk of bias assessment for the included RCTs

erogeneity was not significant $\left(I^{2}=0 \%\right)$. There was no significant publication bias (Egger test, $p=0.98)$.

\section{Functional success}

Six studies (SBS group: 175; SIS group: 173) reported the functional success rates [11, 12, 14-17]. The pooled functional success rates were comparable between SBS and SIS groups (92\% vs. 91.3\%, $p=0.79$, Figure $3 \mathrm{~B}$ ). The heterogeneity was not significant $\left(I^{2}=0 \%\right)$. No significant publication bias was detected (Egger test, $p=0.50$ ).

\section{Total complication}

Six studies (SBS group: 175; SIS group: 173) reported the total complication rates [11, 12, 14-17]. The pooled total complication rates were comparable between SBS and SIS groups (31.4\% vs. $25.4 \%$, $p=0.34$, Figure $3 \mathrm{C}$ ). The heterogeneity was significant $\left(1^{2}=62 \%\right)$. The sensitivity analysis found that the significant heterogeneity disappeared $\left(I^{2}=49 \%\right)$ after removing Naitoh et al. [15] study. The pooled total complication rates were still comparable between SBS and SIS groups $(p=0.72)$. There was no significant publication bias (Egger test, $p=0.29$ ). 
A

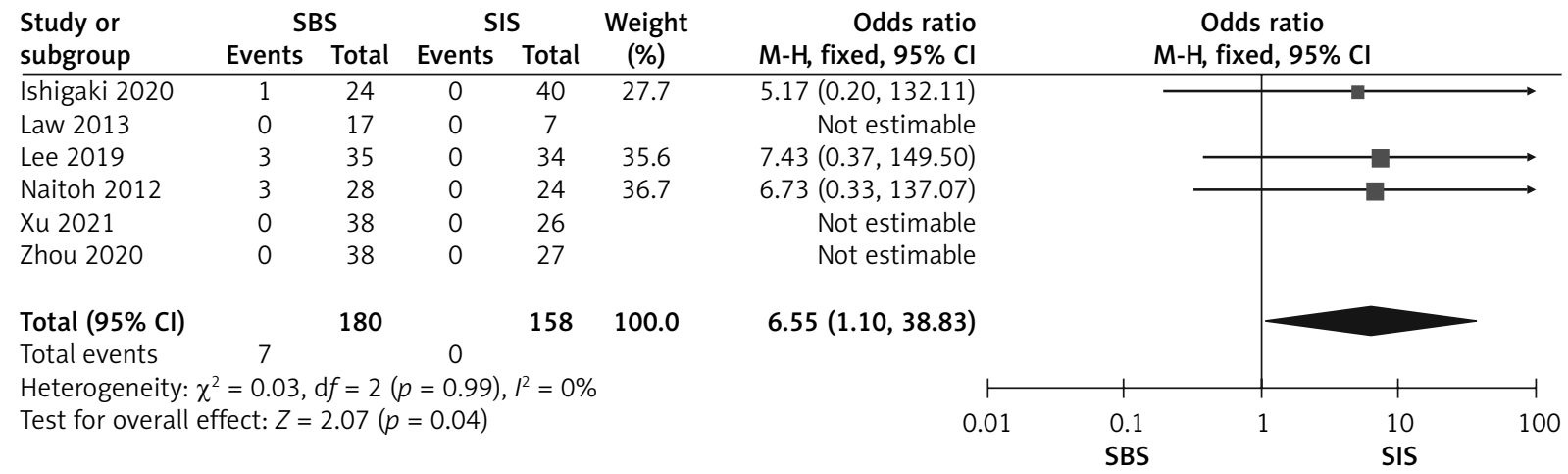

\section{B}

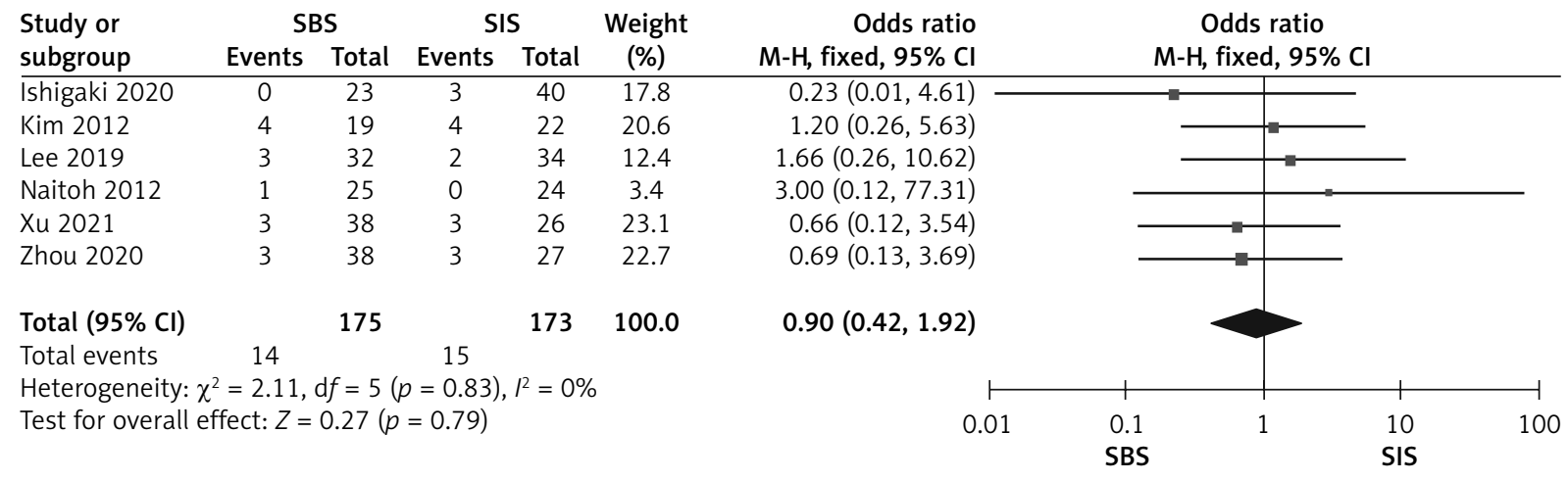

C

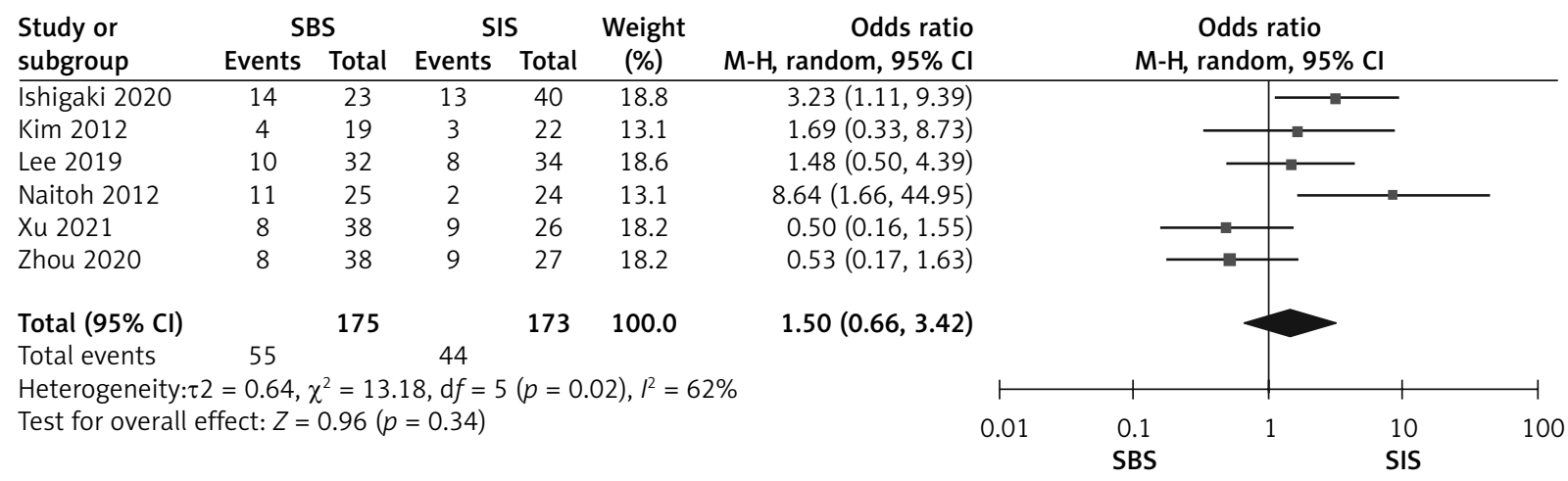

Figure 3. The pooled results of technical success (A), functional success (B), total complication (C) 
D

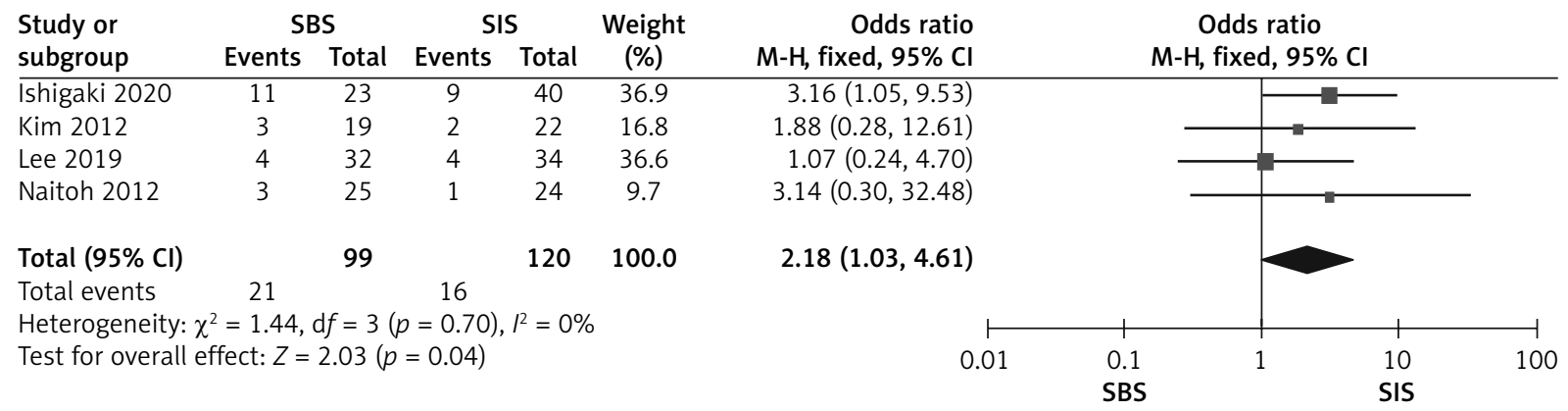

E

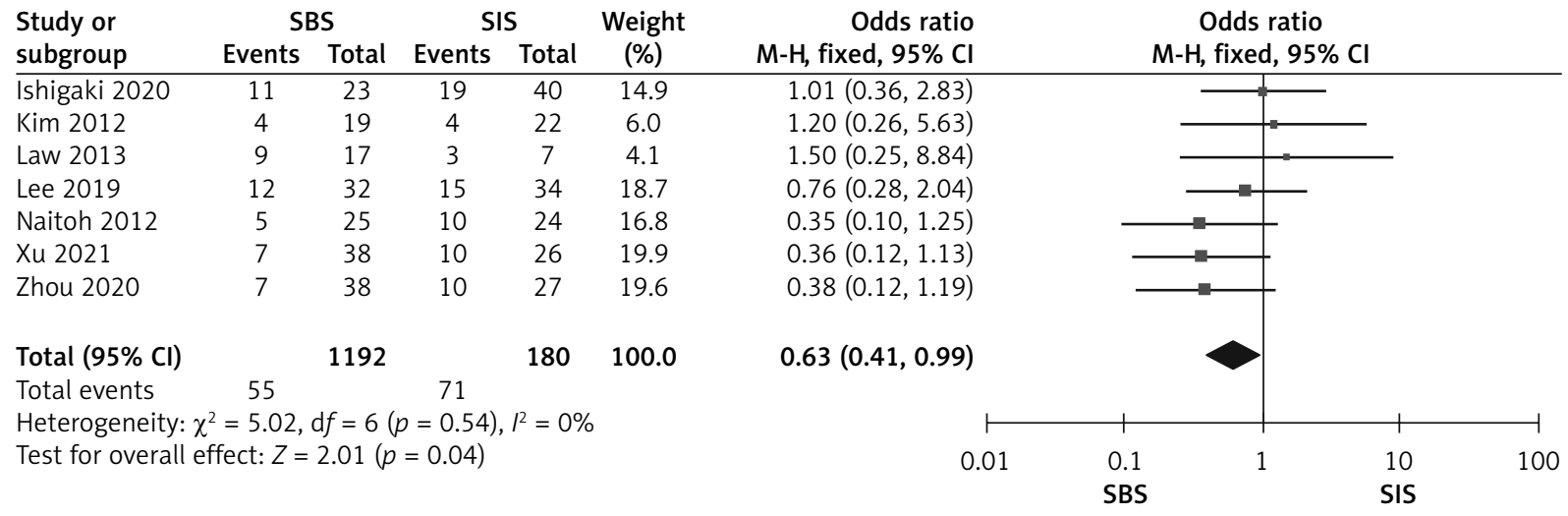

$\mathrm{F}$

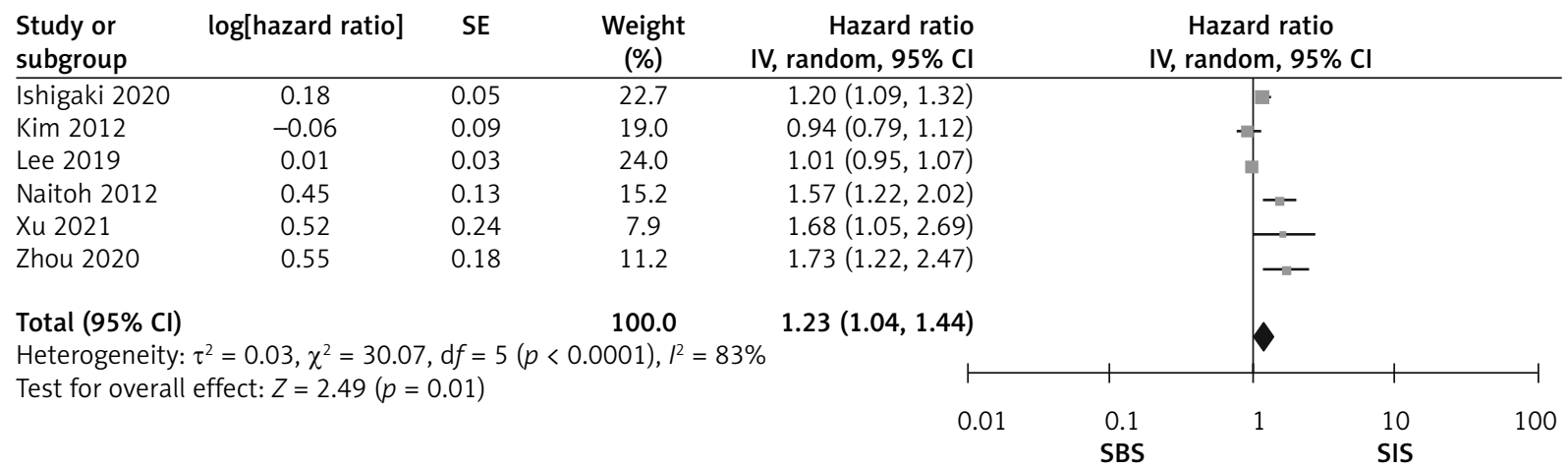

G

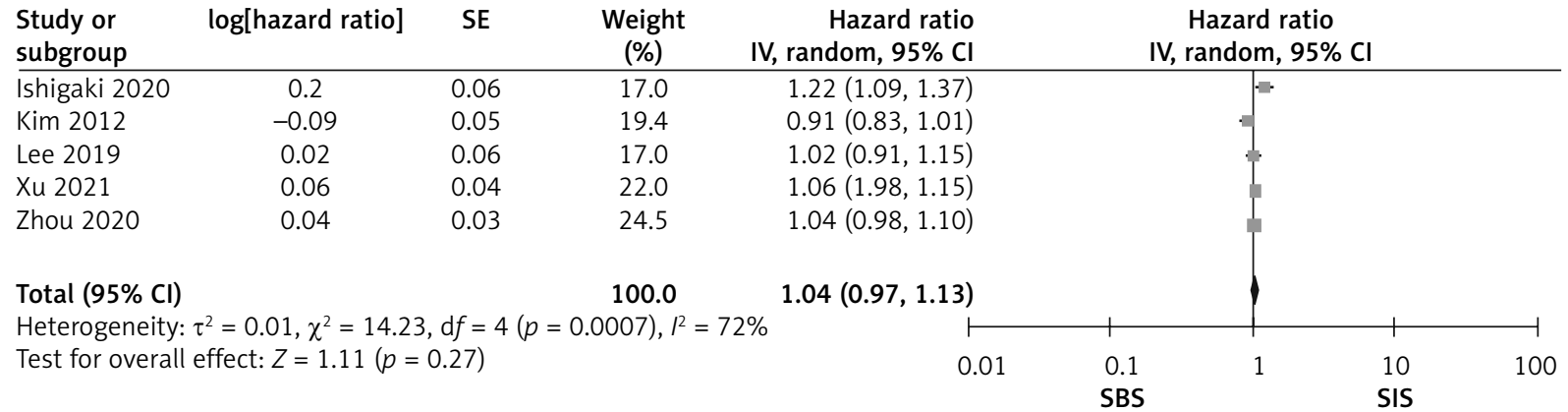

Figure 3. Cont. Early complication (D), stent re-obstruction (E), stent patency (F), and OS (G) in 2 groups 


\section{Early complication}

Four studies (SBS group: 99; SIS group: 120) reported the early complication rates [11, 12, 14, 15]. The pooled early complication rate was significantly lower in the SIS group than in the SBS group (13.3\% vs. $21.2 \%, p=0.04$, Figure $3 \mathrm{D}$ ). The heterogeneity was not significant $\left(r^{2}=0 \%\right)$. There was no significant publication bias (Egger test, $p=0.45$ ).

\section{Re-obstruction}

All studies (SBS group: 192; SIS group: 180) reported the stent re-obstruction rates. The pooled stent re-obstruction rate was significantly lower in the SBS group than in the SIS group $(28.6 \%$ vs. $39.4 \%, p=0.04$, Figure $3 \mathrm{E}$ ). The heterogeneity was not significant $\left(I^{2}=0 \%\right)$. There was no significant publication bias (Egger test, $p=0.43$ ).

\section{Stent patency duration}

The logHR for stent patency duration could be calculated from 6 studies [11, 12, 14-17]. The pooled logHR indicated that the stent patency duration was significantly prolonged in the SBS group relative to the SIS group ( $p=0.01$, Figure $3 \mathrm{~F})$. The heterogeneity was significant $\left(I^{2}=83 \%\right)$. The sensitivity analysis did not find the source of heterogeneity. There was no significant publication bias (Egger test, $p=0.99$ ).

\section{OS}

The logHR for OS could be calculated from 5 studies $[11,12,14,16,17]$. The pooled logHR indicated that the OS was comparable between the SBS and SIS groups ( $p=0.27$, Figure $3 \mathrm{G})$. The heterogeneity was significant $\left(I^{2}=72 \%\right)$. The sensitivity analysis did not find the source of heterogeneity. There was no significant publication bias (Egger test, $p=0.10$ ).

\section{Subgroup analyses}

Table III shows the results of subgroup analyses based on different stenting approaches (endoscopic or percutaneous). When performing endoscopic stenting, SIS technique showed the superiorities in terms of technical success rate $(p=0.04)$, total complication rates $(p=0.007)$, and early complication rates $(p=0.04)$. However, when performing the percutaneous stenting, SBS technique showed the superiorities in terms of stent re-obstruction rate $(p=0.02)$ and stent patency duration $(p=0.0002)$.

Table IV shows the results of subgroup analyses based on different Bismuth types (Bismuth I-IV or IIIV). Based on the patients with Bismuth I-IV MHBO, SIS and SBS techniques showed the similar clinical efficacy. Based on the patients with Bismuth II-IV MHBO, SBS technique showed the superiorities in the terms of stent patency duration $(p=0.01)$ and OS $(p=0.03)$.

Table III. Meta-analytic results based on the studies regarding endoscopic and percutaneous stenting

\begin{tabular}{|c|c|c|c|c|}
\hline Variable & Number of studies & OR or HR $(95 \% \mathrm{Cl})$ & Heterogeneity & Favour \\
\hline \multicolumn{5}{|l|}{ Endoscopic stenting: } \\
\hline Technical success & 4 & $6.55(1.10,38.83), p=0.04$ & $1^{2}=0 \%$ & SIS \\
\hline Functional success & 4 & $1.10(0.41,2.91), p=0.85$ & $1^{2}=0 \%$ & - \\
\hline Total complication & 4 & $2.63(1.31,5.30), p=0.007$ & $I^{2}=15 \%$ & SIS \\
\hline Early complication & 4 & $2.18(1.03,4.61), p=0.04$ & $1^{2}=0 \%$ & SIS \\
\hline Re-obstruction & 5 & $0.80(0.47,1.38), p=0.43$ & $1^{2}=0 \%$ & - \\
\hline Patency & 4 & $1.13(0.97,1.31), p=0.43$ & $I^{2}=84 \%$ & - \\
\hline Overall survival & 3 & $1.04(0.88,1.23), p=0.63$ & $I^{2}=86 \%$ & \\
\hline \multicolumn{5}{|l|}{ Percutaneous stenting: } \\
\hline Functional success & 2 & $0.67(0.20,2.21), p=0.51$ & $1^{2}=0 \%$ & - \\
\hline Total complication & 2 & $0.52(0.23,1.14), p=0.10$ & $I^{2}=0 \%$ & - \\
\hline Re-obstruction & 2 & $0.37(0.17,0.83), p=0.02$ & $I^{2}=0 \%$ & SBS \\
\hline Patency & 2 & $1.71(1.29,2.27), p=0.0002$ & $1^{2}=0 \%$ & SBS \\
\hline Overall survival & 2 & $1.05(1.00,1.10), p=0.05$ & $1^{2}=0 \%$ & \\
\hline
\end{tabular}

$O R$ - odd ratio, HR - hazard ratio, SBS - side-by-side, SIS - stent-in-stent. 
Table IV. Meta-analytic results based on the studies regarding different Bismuth types

\begin{tabular}{|c|c|c|c|c|}
\hline Variable & Number of studies & OR or HR $(95 \% \mathrm{Cl})$ & Heterogeneity & Favour \\
\hline \multicolumn{5}{|l|}{ Bismuth types I-IV: } \\
\hline Functional success & 2 & $1.45(0.37,5.73), p=0.59$ & $I^{2}=0 \%$ & - \\
\hline Total complication & 2 & $3.48(0.84,14.32), p=0.08$ & $1^{2}=33 \%$ & - \\
\hline Early complication & 2 & $2.34(0.54,10.10), p=0.26$ & $1^{2}=0 \%$ & - \\
\hline Re-obstruction & 2 & $0.57(0.22,1.50), p=0.26$ & $I^{2}=31 \%$ & - \\
\hline Patency & 2 & $1.20(0.73,1.99), p=0.46$ & $1^{2}=90 \%$ & - \\
\hline \multicolumn{5}{|l|}{ Bismuth types II-IV: } \\
\hline Technical success & 4 & $5.17(0.20,132.11), p=0.32$ & Not applicable & - \\
\hline Functional success & 3 & $0.55(0.19,1.61), p=0.27$ & $I^{2}=0 \%$ & - \\
\hline Total complication & 3 & $0.96(0.29,3.25), p=0.95$ & $1^{2}=73 \%$ & - \\
\hline Re-obstruction & 4 & $0.61(0.34,1.10), p=0.10$ & $P^{2}=11 \%$ & - \\
\hline Patency & 3 & $1.43(1.08,1.91), p=0.01$ & $I^{2}=64 \%$ & SBS \\
\hline Overall survival & 3 & $1.09(1.01,1.18), p=0.03$ & $1^{2}=65 \%$ & SBS \\
\hline
\end{tabular}

$O R$ - odd ratio, HR - hazard ratio, SBS - side-by-side, SIS - stent-in-stent.

\section{Discussion}

Metal stenting for patients with MHBO is always challenging because the optimal drainage method is not well known [1]. Many meta-analyses have been conducted to compare the clinical effectiveness between unilateral and bilateral stenting for $\mathrm{MHBO}$ [2$4,20,21]$. Although some meta-analyses indicated that unilateral stenting may provide the equal functional success and long-term patency when compared to bilateral stenting $[2,20]$, drainage effectiveness was most closely associated with drainage of $\geq 50 \%$ of the total liver volume, especially for the patients with Bismuth III-IV MHBO [1]. Therefore, bilateral stenting to achieve drainage of $\geq 50 \%$ of the total liver volume may be required for favourable clinical efficacy in patients with MHBO [1].

However, the technical challenges associated with bilateral stenting may preclude its use [1]. Overall technical success rate of SIS and SBS techniques ranges from $73.3 \%$ to $100 \%$ [1]. Each method has its advantages and disadvantages, and deciding on the optimal technique is still difficult. Therefore, a meta-analysis regarding of SBS versus SIS stenting for MHBO is needed.

This meta-analysis provides a comprehensive evaluation of SBS and SIS bilateral stenting for patients with MHBO. First of all, SIS stenting seemed to provide a better technical success. However, the 2 included studies which used percutaneous stenting showed both $100 \%$ technical success rates for SBS and SIS stenting $[16,17]$. A previous meta-analysis also showed that percutaneous SBS bilateral stenting and unilateral stenting were similar in technical success [21]. However, the endoscopic stenting revealed technical success rates to be significantly higher for the SIS group. It is not easy to place two stents simultaneously using the endoscopic approach. Although endoscopic biliary stenting is commonly used, percutaneous biliary stenting is of great value when endoscopic procedures are unsuccessful [22].

The functional success of SBS and SIS bilateral stenting was similar no matter what stenting approaches or Bismuth types were involved. These results might be explained since both SBS and SIS bilateral stenting can drain the bilateral intra-hepatic biliary tracts.

SIS bilateral stenting seemed to result in a lower early complication rate when compared to SBS bilateral stenting. Furthermore, when performing the endoscopic stenting, SIS technique may result in both lower total and early complication rates when compared to SBS technique. This phenomenon may be attributed to that the SBS deployment is distal biliary tract and stricture overexpansion by the two stents [10]. However, SBS and SIS techniques resulted in the similar complication rates in the subgroup of percutaneous stenting. When performing the percutaneous biliary stenting, a temporary drainage catheter is usually placed after stent insertion [23-26]. 
The post-stenting biliary drainage may decrease the early complication rate [8].

Stent re-obstruction and patency duration are the core endpoints of the studies regarding of the stent insertion [27-30]. In this meta-analysis, SBS bilateral stenting showed a significantly lower re-obstruction rate with longer stent patency duration when compared to SIS bilateral stenting. Two possible reasons for these findings can be considered. First, SBS technique provides two spaces for hilar drainage, in contrast to the SIS technique. Second, the hilar region stent mesh is greater in size in the SIS technique relative to the SBS technique, providing more opportunity for tumour ingrowth [15].

The stent patency duration was similar in SBS and SIS groups based on the patients with Bismuth types I-IV. These findings may be influenced by the Bismuth type I patients. Many researchers considered that Bismuth type I patients only require unilateral stenting [31]. In the subgroup of Bismuth types II-IV patients, longer stent duration was still found in the SBS group.

We observed similar OS duration in SBS and SIS groups. This is attributable to the finding that stenting alone has no effect on the tumour itself. Furthermore, the number of patients who received post-operative anticancer therapy was comparable in 2 groups in each included study. In some meta-analyses regarding unilateral and bilateral stenting for MHBO, the OS duration was also not influenced by the stenting techniques [20, 21, 31].

This meta-analysis has some limitations. First, a majority of the included studies are retrospective in nature. Furthermore, each study did not focus on a unique cancer type. These findings increased the risk of bias of this meta-analysis. Second, in these included studies, the anticancer treatments were performed based on the patients' condition and interventional radiologists' experience, these findings may further increase the risk of bias, especially for the endpoints of stent patency and OS. Third, a majority of the included studies are from Asia. Further more comprehensive, worldwide study may be possible when the use of stents becomes more widely used by other countries.

\section{Conclusions}

When comparing the SBS and SIS bilateral stenting for patients with MHBO, although SIS technique may have the superiorities of technical success and early complication rates, the longer stent patency was achieved by the SBS technique. To reduce the technical failure and complication rates when performing the SBS bilateral stenting, percutaneous stenting can be chosen.

\section{Acknowledgments}

This work is supported by the Gansu Natural Science Fund (No. 21JR7RA573).

\section{Conflict of interest}

The authors declare no conflict of interest.

\section{References}

1. Lee TH, Moon JH, Park SH. Biliary stenting for hilar malignant biliary obstruction. Dig Endosc 2020; 32: 275-86.

2. Aghaie Meybodi M, Shakoor D, Nanavati J, et al. Unilateral versus bilateral endoscopic stenting in patients with unresectable malignant hilar obstruction: a systematic review and meta-analysis. Endosc Int Open 2020; 8: E281-90.

3. Yang F, Wang X, Xia F, et al. Endoscopic metal stenting for malignant hilar biliary obstruction: an update meta-analysis of unilateral versus bilateral stenting. Videosurgery Miniinv 2021; 16: 472-81.

4. Ashat M, Arora S, Klair JS, et al. Bilateral vs unilateral placement of metal stents for inoperable high-grade hilar biliary strictures: a systemic review and meta-analysis. World J Gastroenterol 2019; 25: 5210-9.

5. Jha AK, Jha P, Jha SK, et al. Plastic versus metal stents for inoperable gallbladder cancer with hilar biliary obstruction: the jury is still out. Ann Gastroenterol 2021; 34: 12-9.

6. Jang SI, Lee DK. Update on pancreatobiliary stents: stent placement in advanced hilar tumors. Clin Endosc 2015; 48: 201-8.

7. Rerknimitr R, Angsuwatcharakon P, Ratanachu-ek T, et al. Asia-Pacific consensus recommendations for endoscopic and interventional management of hilar cholangiocarcinoma. J Gastroenterol Hepatol 2013; 28: 593-607.

8. Fu YF, Zhou WJ, Shi YB, et al. Percutaneous stenting for malignant hilar biliary obstruction: a randomized controlled trial of unilateral versus bilateral stenting. Abdom Radiol (NY) 2019; 44: 2900-8.

9. Sawas T, Al Halabi S, Parsi MA, et al. Self-expandable metal stents versus plastic stents for malignant biliary obstruction: a meta-analysis. Gastrointest Endosc 2015; 82: 256-67.e7.

10. Moon JH, Rerknimitr R, Kogure $\mathrm{H}$, et al. Topic controversies in the endoscopic management of malignant hilar strictures using metal stent: side-by-side versus stent-in-stent techniques. J Hepatobiliary Pancreat Sci 2015; 22: 650-6.

11. Ishigaki K, Hamada T, Nakai Y, et al. Retrospective comparative study of side-by-side and stent-in-stent metal stent placement for hilar malignant biliary obstruction. Dig Dis Sci 2020; 65: 3710-8. 
12. Kim KM, Lee $\mathrm{KH}$, Chung $\mathrm{YH}$, et al. A comparison of bilateral stenting methods for malignant hilar biliary obstruction. Hepatogastroenterology 2012; 59: 341-6.

13. Law R, Baron TH. Bilateral metal stents for hilar biliary obstruction using a $6 \mathrm{Fr}$ delivery system: outcomes following bilateral and side-by-side stent deployment. Dig Dis Sci 2013; 58: 2667-72.

14. Lee TH, Moon JH, Choi JH, et al. Prospective comparison of endoscopic bilateral stent-in-stent versus stent-by-stent deployment for inoperable advanced malignant hilar biliary stricture. Gastrointest Endosc 2019; 90: 222-30.

15. Naitoh I, Hayashi K, Nakazawa T, et al. Side-by-side versus stent-in-stent deployment in bilateral endoscopic metal stenting for malignant hilar biliary obstruction. Dig Dis Sci 2012; 57 : 3279-85.

16. Xu H, Xu C, Gu J, et al. Clinical efficacy comparison of two percutaneous biliary stent implantation techniques in treating malignant hilar biliary obstruction. J Intervent Radiol 2021; 30 403-7.

17. Zhou WZ, Liu S, Yang ZQ, et al. Percutaneous stent placement for malignant hilar biliary obstruction: side-by-side versus stent-in-stent technique. BMC Gastroenterol 2020; 20: 174.

18. Moher D, Liberati A, Tetzlaff J, et al. Preferred reporting items for systematic reviews and meta-analyses: the PRISMA statement. BMJ 2009; 339: b2535.

19. Cook DA, Reed DA. Appraising the quality of medical education research methods: the Medical Education Research Study Quality Instrument and the Newcastle-Ottawa Scale-Education. Acad Med 2015; 90: 1067-76.

20. Fu YF, Xu YS, Shi YB, et al. Percutaneous metal stenting for malignant hilar biliary obstruction: a systematic review and meta-analysis of unilateral versus bilateral stenting. Abdom Radiol 2021; 46: 749-56.

21. Chen ZK, Zhang W, Xu YS, et al. Unilateral versus side-by-side metal stenting for malignant hilar biliary obstruction: a meta-analysis. J Laparoendosc Adv Surg Tech A 2021; 31: 203-9.

22. Gupta P, Maralakunte M, Rathee S, et al. Percutaneous transhepatic biliary drainage in patients at higher risk for adverse events: experience from a tertiary care referral center. Abdom Radiol 2020; 45: 2547-53.

23. Sha KH, Liu TG, Yang F, et al. Irradiation stent insertion for in operable malignant biliary obstruction: a meta-analysis of randomized controlled trials. Abdom Radiol 2021; 46: 2173-81.

24. Lin J, Wu AL, Teng F, et al. Stent insertion for inoperable hilar cholangiocarcinoma: comparison of radioactive and normal stenting. Medicine 2021; 100: e26192.

25. Teng F, Xian YT, Lin J, et al. Comparison of unilateral with bilateral metal stenting for malignant hilar biliary obstruction. Surg Laparosc Endosc Percutan Tech 2019; 29: 43-8.

26. Chang G, Xia FF, Li HF, et al. Unilateral versus bilateral stent insertion for malignant hilar biliary obstruction. Abdom Radiol 2017; 42: 2745-51.

27. Yin X, Li DM, Yang F, et al. Self-expanded metallic stent insertion for hilar cholangiocarcinoma: comparison of unilateral and bilateral stenting. J Laparoendosc Adv Surg Tech A 2019; 29: 1501-6
28. Huang $Y Y, X u X J$, Huang $X Z$, et al. A stent with radioactive seed strand insertion for inoperable malignant biliary obstruction: a meta-analysis. Brachytherapy 2021; 20: 638-44.

29. Yang ZM, Geng HT, Wu H. Radioactive stent for malignant esophageal obstruction: a meta-analysis of randomized controlled trials. J Laparoendosc Adv Surg Tech A 2021; 31: 783-9.

30. Meng QK, Yu XY, Li W, et al. Radioactive and normal stent insertion for the treatment of malignant airway stenosis: a meta-analysis. Brachytherapy 2021; 20: 883-91.

31. Li M, Wu W, Yin Z, et al. Unilateral versus bilateral biliary drainage for malignant hilar obstruction: a systematic review and meta-analysis. Zhonghua Gan Zang Bing Za Zhi 2015; 23: 118-23.

Received: 11.10.2021, accepted: 25.10.2021. 